Изв. АН Эстонии. Геол., 1990, 39, № 4, 155-161

УДК $523.51(571.6)$

Энн ПНРРУС, Реэт ТИЙРМАА

\title{
ФРАГМЕНТ СИХОТЭ-АЛИНСКОГО МЕТЕОРИТНОГО ДОЖДЯ В КОЛЛЕКЦИИ ИНСТИТУТА ГЕОЛОГИИ АҚАДЕМИИ НАУК ЭСТОНИИ
}

Выпавший 12 февраля 1947 г. в горах Сихотэ-Алиня метеоритный дождь относится к уникальным явлениям природы. Своими выходами к познанию процесса дробления крупного метеоритного тела в нижних слоях атмосферы, рассеивания метеоритного вещества и формирования небольших кратерообразных структур на поверхности Земли он приковывает внимание специалистов по сей день.

По случаю 40-летия падения Сихотэ-Алинского метеорита Комитетом по метеоритам АН СССР осенью 1987 г. была организована крупная научная экспедиция с участием представителей различных институтов и организаций. Главной целью экспедиции был сбор метеоритного вещества в тыловой части эллипса рассеивания, характеризующего процесс дробления на конечном отрезке падения метеорита, и извлечение из грунта труднодоступной горной тайги еще оставшихся там индивидуальных экземпляров. Морфометрический и статистический анализы этого материала позволили бы количественно уточнить многие важные параметры падения метеорита.

В работе экспедиции принимала участие и группа из Института геологии АН Әстонии (авторы, Ааза Аалоэ, Т. Калласте, Ю. Кестлане, А. Раукас и Х. Тынисон), которой был обследован поисковый участок № 18. Этот участок расположен в 2,5 км севернее центра кратерного поля, на левом берегу р. Большая Метеоритная, на западном склоне водораздельного хребта, состоящего из небольших по высоте сопок (рис. 1). Первоначально планировалось тщательно обследовать квадратный участок площадью $100 \times 100$ м, однако из-за лесных завалов на части территории пришлось ограничиться двумя сдвинутыми относительно друг друга блоками (рис. 2) общей площадью тоже 1 га. Участок был покрыт густым смешанным лесом, за исключением мест выборочной рубки ценного кедра.

С помощью миноискателя, которым была «прослушана» площадь всего участка, из грунта были извлечены 131 метеорит и другие металлические предметы. Несмотря на отдельные крупные завалы из деревьев и хвороста, удалось обследовать не менее $95 \%$ всей площади участка. Не исключая возможности пропуска миноискателем некоторых металлических предметов, можно все же с уверенностью утверждать, что найдено не менее $80 \%$ или даже $85-95 \%$ всех залегающих в приповерхностном слое (до 5-15 см) искомых объектов. О скрупулезности поисков говорит тот факт, что в ходе работы были «подняты» на поверхность такие предметы, как витки и обрывки стального троса, три гайки, металлическая пуговица, наконечник первобытной стрелы, колпачок охотничьего патрона, утерянный кем-то из участников экспедиции сувенирный значок.

В итоге собранные на участке № 18 метеориты составили представительную цельную коллекцию, характеризующую среднюю часть эллипса 
рассеивания Сихотэ-Алинского метеоритного дождя. Она хорошо привязана к структуре объекта и ее основные характеристики могут стать опорными при проведении в дальнейшем различных расчетов и реконструкций.

Коллекция хранится в специальном фонде Института геологии АН Эстонии. После измерения и взвешивания образцов малая их часть (восемь типовых экземпляров) была депонирована в коллекцию Комитета по метеоритам АН СССР и сделаны соответствующие ссылки в нашей коллекции. Учитывая, что информация об этой коллекции должна быть доступной для всех интересующихся проблемами метеоритики, изложим ниже ее главные особенности.

Все извлеченные из грунта участка № 18 образцы (в количестве 131-го) представляют собой индивидуальные метеориты с резко выраженными по сторонам регмаглиптами или с менее выраженными следами плавления поверхности (рис. 3). Осколков метеорита среди них нет. Следовательно, все найденные метеориты образовались не в результате соударения космического тела с Землей, а в результате его дробления в атмосфере.

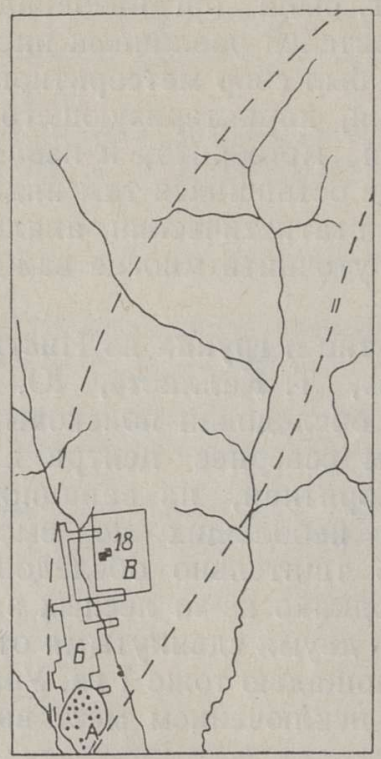

Рис. 1. Схема обследованных площадей на месте падения Сихотэ-Алинского метеоритного дождя.

А - кратерное поле, Б - зона системного сбора метеоритов в 1967-1973 гг., В - зона сбора метеоритов в 1985 и 1987 гг., 18 - участок сбора коллекции Института геологии АН Эстонии. Пунктиром показана предполагаемая граница эллипса рассеяния метеоритного дождя (по В. И. Цветкову, 1983).

Рис. 2. Распределенне метеоритов по количеству (а), по массе, г (б - суммарно, в - в среднем), по средней величине, мм (г) на площади участка № 18.
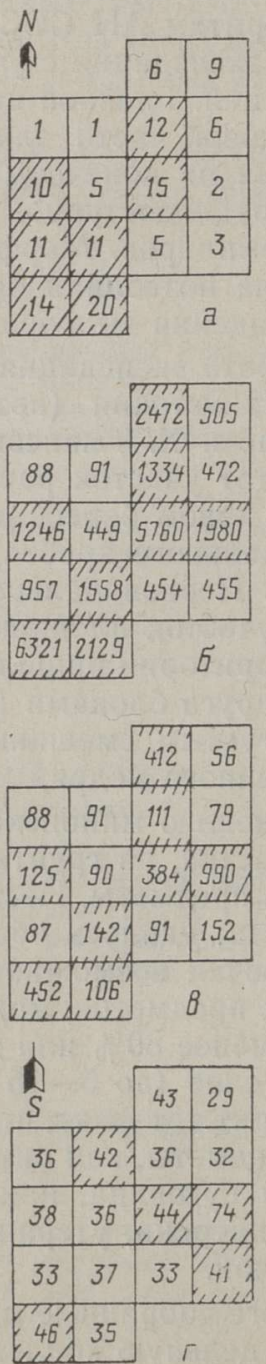


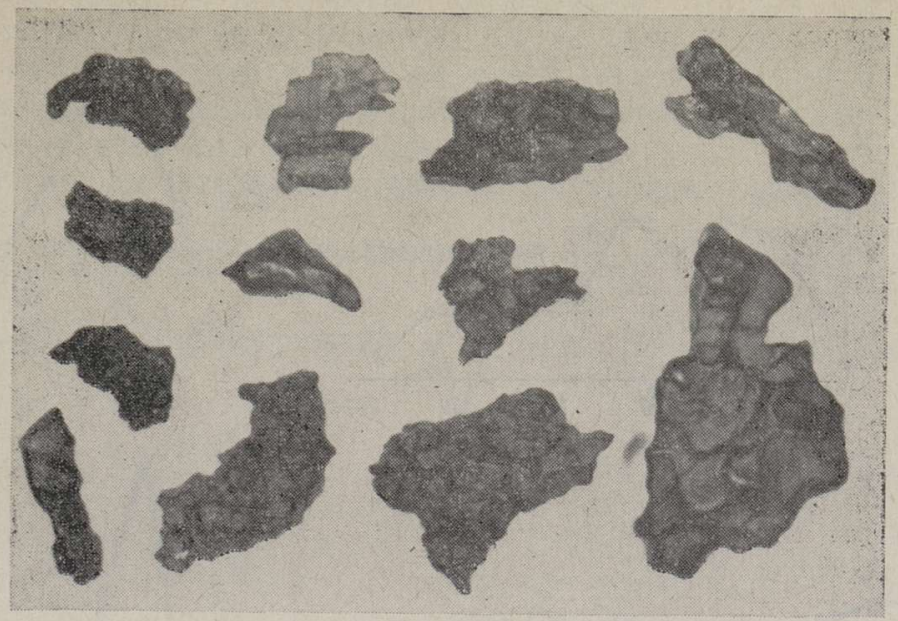

Рис. 3. Типичные представители индивидуальных метеоритов с участка № 18 . Уменьш. $2 \times$.

Количественное распределение упавших на исследованный участок метеоритов весьма неравномерное (рис. 2, а), но явно прослеживается тенденция их концентрации в юго-западном квадрате участка (56 метеоритов - $43 \%$ ), что в целом отражает распределение метеоритного вещества Сихотэ-Алинского падения. По распределению суммарной массы метеоритов эта закономерность также выдерживается (рис. 2, б) - максимум $(10,965$ кг - 42\%) приходится на юго-западную четверть участка, т.е. на ближайшую к оси эллипса рассеивания часть. По средней массе одного метеорита наблюдается несколько иная закономерность (рис. 2, в) - материал наиболее тяжеловесен на восточной оконечности участка. То же самое, естественно, отражается и в средних размерах метеоритов (рис. 2,г).

Суммарная кривая распределения метеоритов по массе (рис. 4) оправдала ожидания - коллекция имеет одномодальное распределение с максимумом в части малых масс (до 200 г), а образцы экстремально крупных размеров единичны. Такая картина согласуется с представлением о многофазном дроблении метеорита в нижних слоях атмосферы (Кринов, 1975) и соответствующей сортировке частиц по траектории падения. Однако, анализируя область распределения метеоритов участка на более растянутой шкале графика, легко убедиться, что сортировка метеоритов по массе весьма слаба и ни в коем случае не сравнима с сортировкой соизмеримых частиц, например, в водной среде. В этом отражаются прежде всего особенности метеоритного дождя - падение его в нагретом воздухе при значительном воздействии начальной энергии космических частиц, а в данном случае - и небольшая высота дробления главного тела метеорита.

Принципиально такая же картина наблюдается и в распределении метеоритов по величине длинной оси (рис, 5 , а) и по среднему пересечению (рис. 5, б).

По своей морфологии индивидуальные метеориты достаточно разнообразны (рис. 3), они представляют почти все рубрики классификации Кринова (Кринов, 1975). Однако следует отметить, что явно преобладают полиэдрические формы, а среди них - неправильно-угловатые (рис. 6, а). Среди округлых не найдено ни конических, ни линзовидных форм, а черепкообразные или округло-угловатые отнесены к соответствующим группам условно, так как округлые участки выражены на 


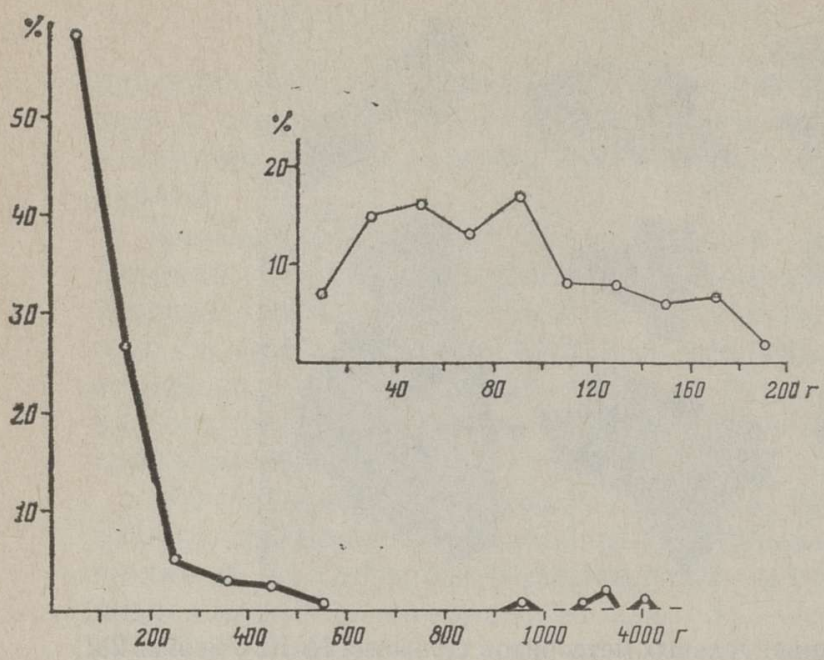

Рис. 4. Распределение метеоритов коллекции по мacce.

Рис. 5. Распределение метеоритов коллекции по наибольшему (а) и среднему (б) размерам.
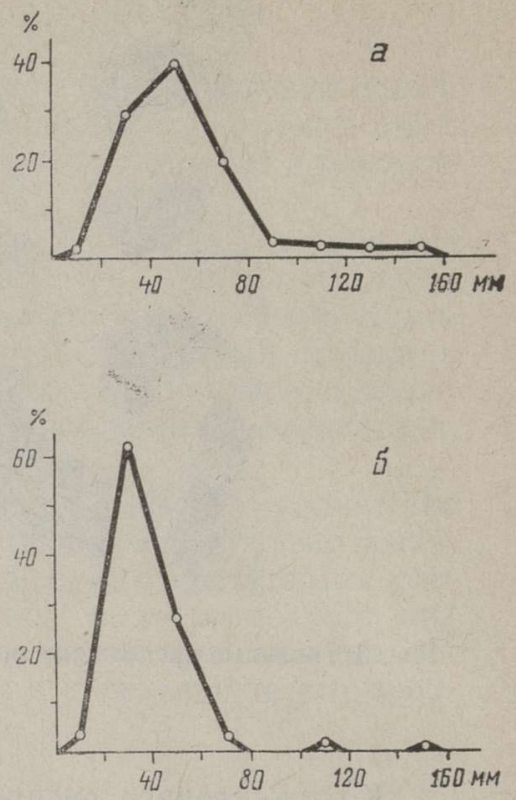

поверхности не всегда достаточно четко. Эти особенности также свидетельствуют о том, что в данной части эллипса рассеивания метеоритного дождя преобладают продукты дробления, проделавшие после отделения от материнского тела лишь небольшой путь в нагретом воздухе.

Проведя анализ форм метеоритов методом измерения трех основных перпендикулярно расположенных осей $A, B$ и $C$, предложенным Т. Цингом (Zingg, 1935), получили следующее распределение их по основным типам (рис. 6,6$)$. Уплощенные тела составляют около $20 \%$ всей совокупности метеоритов, а равноосные, близкие к изометрическим, - около $25 \%$. Большинство метеоритов принадлежит к удлиненному (призматическо-цилиндрическому) типу (около $36 \%$ ), а трехосные (эллипсоидальные) не превышают 19\%. Однако достаточная представленность всех основных морфологических типов в данной совокупности позволяет все же говорить о слабом структурном контроле процесса дробления метеорита. Акт дробления его был очень кратковременным, вследствие чего
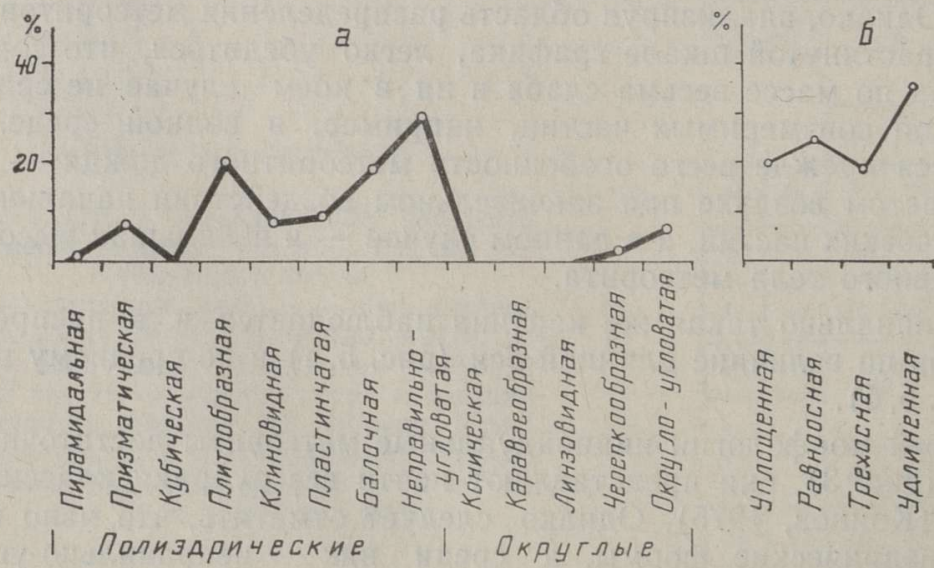

$\therefore$

Рис. 6. Распределение метеоритов коллекции по морфологии: а - по классификации Кринова (Кринов, 1975), б - по классификации Цинга (Zingg, 1935), т. е. по соотношению перпендикулярных осей $B: A$ и $C: B$, 
хотя в совокупности и преобладают удлиненные формы, они все же вытянуты в одном направлении слабо - соответствующий коэффициент большинства тел не превышает $1,0-2,0$. Одномодальное распределение имеют метеориты и по коэффициенту уплощенности - в пределах значения $1,0-2,5$. Есть только один сильно уплощенный (листообразный) метеорит с коэффициентом 4,6. Интересно распределение по изометричности - выявляются образцы с отчетливо одномодальным распределением при низких значениях коэффициента $(0,1-0,5)$ и отличающийся от основной части коллекции материал с высокой изометричностью $(0,6-$ $0,9)$. Возможно, что именно в этом случае оказал свое влияние структурный контроль процесса дробления - склонность к образованию октаэдрических обломков метеорита.

Судя по распределению основных морфологических типов (по соответствующим коэффициентам) (рис. 8), в целом отчетливой корреляции между размерами метеоритов и их тел ни в одном случае не выявляется. Однако следует отметить, что все вытянутые в одном направлении тела (с коэффициентом удлиненности $>2,5$ ) сосредоточиваются в узком интервале среднего размера от 20 мм до 40 мм, т. е. имеют наименьший размер в пределах 8-10 мм, что хорошо соответствует пересечению удлиненных кристаллов метеоритного железа, наблюдаемых в «балочных» формах метеоритов. Следовательно, именно крупнокристаллическая структура исходного метеорита наиболее отчетливо отражается в форме индивидуальных метеоритов данной размерности - т. е. структурный контроль дробления все же налицо. В какой-то степени эта закономерность улавливается и по коэффициенту уплощенности, однако на более ограниченном материале. Здесь могли сыграть роль параллельные сростки «балочных» кристаллов исходного метеорита. Следует сказать, что все экстремально крупные метеориты, найденные на площади участка № 18 , слабо индивидуализированы по морфологии (рис. 8).

Коллекция участка № 18 входит в состав коллекции метеоритов Института геологии АН Эстонии под отдельным номером SA30/18. Meтеориты имеют изначальный вид, они не подвергались обработке химикатами и опробованию. Желающим ознакомиться с коллекцией высылаются копии таблиц с первичными данными измерения метеоритов.

Авторы выражают благодарность коллегам Аазе Аалоэ, Т. Калласте, Ю. Кестлане, А. Раукасу и Х. Тынисону за содействие при сборе материала коллекции,

\section{Л ИТЕРАТУРА}

Кринов Е. Л. Дробление Сихотэ-Алинского метеоритного тела // Метеоритика, вып. 34. M., 1975, 3-14.

Цветков В. И. Некоторые особенности поверхностного рассеяния Сихотэ-Алинского метеоритного дождя // Астрон. вестн., 1973, VII, № 2, 107-110.

Цветков В. Н. Связь дробления и рассеяния Сихотэ-Алинского метеоритного дождя со структурой метеорита // Астрон. вестн., 1983, XVII, № 2, 122-126.

Zingg, Th. Beiträge zur Schotteranalyse // Schweiz. Mineral Petrogr. Mitt., 1935, 15, 39-140.

Институт геологии

Академии наук Эстонии
Поступила в редакцию 26/IV 1990 


\section{SIHHOTE-ALINI METEORIIDISAJU OSA GEOLOOGIA INSTITUUDI KOLLEKTSIOONIS}

On esitatud 1987. aastal uurimisväljakult nr. 18 kogutud tervikulise meteoriidikollektsiooni (131 eksemplari) lühikirjeldus. Kollektsioon iseloomustab meteoriidisaju hajumisareaali keskosa. Meteoriitide mỗotmisandmed, väliskuju ja statistiline jaotuspilt on lähteandmeteks unikaalse meteoriidisaju langemis- ja tükeldumisparameetrite täpsustamisel.

\section{Enn PIRRUS and Reet TIIRMAA}

\section{SIKHOTE-ALIN METEORITES IN THE COLLECTION \\ OF THE INSTITUTE OF GEOLOGY, ESTONIAN ACADEMY OF SCIENCES}

A short description of the meteorite collection (131 specimens) collected in 1987 in the exploration field No. 18 is presented. The collection characterizes the central part of the scattering area of the meteorite fall (Fig. 1). The distribution of the meteorites on the studied 1 ha area is uneven judging by their number as well as sizes (Fig. 2), their shapes are variable (Fig. 3). Small meteorites with the mass less than $200 \mathrm{~g}$ are dominating (Fig. 4), however, they are not clearly sorted. The longitudinal diameter of the meteorites is mostly $40-50 \mathrm{~mm}$, their median diameter is $30-40 \mathrm{~mm}$ (Fig. 5). Among the meteorites only single bigger specimens occur. Isometric and plate-shaped specimens are less numerous, while sligtly elongated forms are prevailing (Fig. 6). In the classifications used the meteorite finds are grouped rather evenly and without any firm rule (Fig. 7). This allows us to suggest that the meteorite fall in this region comprised pieces of irregular shapes which are not particularily subjected to structural control and sorting in the air or to thermal processing affecting their morphology. The relationship between the shapes and sizes of the meteorites is not clearly expressed in the collection studied (Fig. 8).

The collection is preserved at the Institute of Geology, the Estonian Academy of Sciences, in its original state. In case of need additional information will be presented. 